\title{
Nutrition and health profile of elderly females residing in old age homes in four major cities of Gujarat
}

\author{
Komal Chauhan, Pallavi Mehta, Hemangini Gandhi, Annapurna Maity and Hetal Shah
}

\begin{abstract}
India is witnessing demographic transition leading to rapid increase in number of elderly and old age homes. There is dearth of information about problems related to health, nutritional status and quality of life of the institutionalized elderly in many parts of the country. Objectives: Analysis of the old age homes (institutions) and nutrition and health profile of the elderly females residing in old age homes of major cities of Gujarat. Methods: Baseline data on basic infrastructures and facilities available in 12 old age homes of four major cities (Ahmedabad, Rajkot, Surat and Vadodara) of Gujarat state were collected. Baseline data on nutritional status, life style, general and metal health (GDI, CIT and MMSE) profile of 149 institutionalized elderly females aged $\geq 60$ years were also collected. Results: Institutional profile revealed that old age homes of Ahmedabad and Baroda offered better facilities. Poor dietary and other facilities were offered by the old age homes in Rajkot. 75 per cent institutes provided first aid and emergency hospital facilities. Only 7 homes provided less than 3 meals per day. Mean age of the female elderly was 74 years. 33.6 per cent and 14.8 per cent subjects were overweight and obese, respectively. Anemia was prevalent in more than 45 per cent subjects. Dietary intake of protein, fibres, iron and $\beta$-carotene was less than the RDA. Problems of oral cavity, pain in joints, mobility, vision, neurological problem, sleep disturbance, constipation etc. were prevalent among the subjects. GDI scores showed no significant difference between the age groups and inmates of different cities but showed a significant $(\mathrm{P}<0.01)$ difference in MMSE and CIT scores. Conclusion: Location, environment, activities and meal pattern might have influence on health of the elderly. Better dietary health care with good recreation activities and long term observational as well as interventional studies are recommended for old age home.
\end{abstract}

Key Words : Old age homes, Institutionalized female elderly, Health and nutritional status

How to cite this article : Chauhan, Komal, Mehta, Pallavi, Gandhi, Hemangini, Maity, Annapurna and Shah, Hetal (2014). Nutrition and health profile of elderly females residing in old age homes in four major cities of Gujarat. Food Sci. Res. J., 5(2): 75-80.

Author for correspondence :

KOMAL CHAUHAN, Department of Foods and Nutrition, The Maharaja

Sayajirao University of Baroda, VADODARA (GUJARAT) INDIA

Associate Authors' :

PALLAVI MEHTA, HEMANGINI GANDHI, ANNAPURNA MAITY AND

HETAL SHAH, Department of Foods and Nutrition, Faculty of Family and

Community Sciences, The Maharaja Sayajirao University of Baroda, VADODARA (GUJARAT) INDIA 